University of Wollongong

Research Online

Faculty of Engineering and Information

Faculty of Engineering and Information

Sciences - Papers: Part A

Sciences

$1-1-2015$

Energy loss at bends in the pneumatic conveying of fly ash

Naveen Tripathi

Thapar University

A Sharma

Queensland University of Technology

Soumya Suddha Mallick

Thapar University, ssm672@uow.edu.au

Peter W. Wypych

University of Wollongong, wypych@uow.edu.au

Follow this and additional works at: https://ro.uow.edu.au/eispapers

Part of the Engineering Commons, and the Science and Technology Studies Commons

Research Online is the open access institutional repository for the University of Wollongong. For further information contact the UOW Library: research-pubs@uow.edu.au 


\title{
Energy loss at bends in the pneumatic conveying of fly ash
}

\begin{abstract}
An accurate estimation of the total pressure drop of a pipeline is important to the reliable design of a pneumatic conveying system. The present paper presents results from an investigation into the modelling of the pressure drop at a bend in the pneumatic conveying of fly ash. Seven existing bend models were used (in conjunction with solids friction models for horizontal and vertical straight pipes, and initial acceleration losses) to predict the total pipeline pressure drop in conveying fly ash (median particle diameter: $30 \mu \mathrm{m}$; particle density: $2300 \mathrm{~kg} / \mathrm{m}^{3}$; loose-poured bulk density: $700 \mathrm{~kg} / \mathrm{m}^{3}$ ) in three test rigs (pipelines with dimensions of $69 \mathrm{~mm}$ inner diameter (I.D.) $\times 168 \mathrm{~m}$ length; $105 \mathrm{~mm}$ I.D.x $168 \mathrm{~m}$ length; $69 \mathrm{~mm}$ I.D.x554m length). A comparison of the pneumatic conveying characteristics (PCC) predicted using the seven bend models and experimental results shows that the predicted total pipeline PCC and trends depend on the choice of bend model. While some models predict trends that agree with the experimental results, other models predicted greater bend pressure drops for the dense phase of fly ash than for the dilute phase. Models of Pan, R. (1992). Improving scale-up procedures for the design of pneumatic conveying systems. Doctoral dissertation, University of Wollongong, Australia, Pan, R., \& Wypych, P.W. (1998). Dilute and dense phase pneumatic conveying of fly ash. In Proceedings of the sixth International Conference on Bulk Materials Storage and Transportation (pp. 183-189), Wollongong, NSW, Australia and Chambers, A.J., \& Marcus, R.D. (1986). Pneumatic conveying calculations. In Proceedings of the second International Conference on Bulk Materials Storage and Transportation (pp. 49-52), Wollongong, Australia reliably predicted the bend losses for systems conveying fly ash over a large range of air flows.
\end{abstract}

\section{Keywords}

pneumatic, bends, ash, loss, fly, energy, conveying

Disciplines

Engineering | Science and Technology Studies

\section{Publication Details}

Tripathi, N., Sharma, A., Mallick, S. S. \& Wypych, P. W. (2015). Energy loss at bends in the pneumatic conveying of fly ash. Particuology: science and technology of particles, 21 65-73. 


\title{
An Investigation into Energy Loss in Bends for Pneumatic Conveying of Fly Ash
}

\author{
Naveen Tripathi $^{\mathrm{a}}$, Atul Sharma ${ }^{\mathrm{a}}$, S.S.Mallick ${ }^{\mathrm{a}}$ and P.W.Wypych ${ }^{\mathrm{b}}$ \\ ${ }^{\mathrm{a}}$ Department of Mechanical Engineering, Thapar University, Patiala, Punjab-147004, India \\ ${ }^{b}$ Faculty of Engineering and Information Sciences, University of Wollongong, \\ Wollongong, NSW-2500, Australia
}

\begin{abstract}
An accurate estimation of the total pipeline pressure drop is of significant importance for the reliable design of a pneumatic conveying system. The present paper presents results from an investigation into the modelling of bend pressure drop for pneumatic conveying of fly ash. Seven existing bend models were used (in conjunction with solids friction models for straight pipes, verticals and initial acceleration losses) to predict the total pipeline pressure drop for conveying of fly ash (median particle diameter: $30 \square \mathrm{m}$; particle density: $2300 \mathrm{~kg} / \mathrm{m}^{3}$; loosepoured bulk density: $700 \mathrm{~kg} / \mathrm{m}^{3}$ ) in three test rigs: $69 \mathrm{~mm}$ I.D. x $168 \mathrm{~m}$ long; $105 \mathrm{~mm}$ I.D. x 168 m long; 69 mm I.D. x 554 m long pipes. A comparison amongst the predicted pneumatic conveying characteristics (PCC) using all seven bend models (and the experimental plots) indicated that the values of predicted total pipeline PCC and trends significantly depend to the choice of bend models. While some models have provided trends confirming to the experimental plots, some other models resulted in prediction of higher bend pressure drop values in dense-phase than in dilute-phase. Pan (1992), Pan and Wypych (1998) and Chambers and Marcus (1986) models are found to be suitable to reliably predict the bend losses for fly ash conveying systems over a large range of air flows.
\end{abstract}

Keywords: Pneumatic conveying; fluidised dense-phase; bend; pressure drop; bend model 


\section{Introduction}

Pneumatic conveying is the process of transportation of dry bulk materials through pipelines with the help of air or other non-reacting gases. This process is being used in several industries, such as in thermal power plants (to convey pulverised coal and fly ash), cement, chemical, food, petrochemical plants etc. The various reasons to use this mode of transport are ease of totally enclosed system, flexible layout, automation and control, dust free, hygienic and being environmental friendly. The conventional mode of conveying is known as the dilute phase (suspension flow) conveying, where the velocity of gas is sufficiently high to suspend the particles in the pipeline. However, to obtain the increasingly demand of industries such as new product and process, improved quality etc, several modes of dense phase (non-suspension flow)have been developed to take the advantage of particular product properties (e.g. aeration characteristics). An accurate estimation of minimum transport boundary and total pipeline pressure drop are important criteria for thereliable design of pneumatic conveying systems. Under-prediction of minimum transport boundary (i.e. minimum conveying air requirement) would result in either reduced throughput or line blockage. Total pipeline pressure drop consists of losses due to horizontal straight pipes, bends, verticals and initial acceleration of particles from the rest. Accurate prediction of pressure loss for each, especially the horizontal pipe, vertical and bend losses, is very important as they form the significant share of total pipeline losses. For straight pipe losses Barth (1958) proposed equation (1) for pressure drop $\square$ P) for solid-gas flow. This equation is believed to be originally proposed for dilute phase transport of coarse particles. However, various researchers such as Stegmaier (1978), Weber (1981), Pan (1992), Pan and Wypych (1998) and Jones et al. (2003) employed this expression to predict the pressure loss for dense- 
phase flow of fine powders (such as fly ash, cement, pulverised coal etc) through straight pipes.

$\Delta p=\left(\lambda_{f}+m^{*} \lambda_{s}\right) \frac{\rho \cdot L \cdot V^{2}}{2 \cdot D}$

In comparison to the relatively higher proportion of efforts that have been directed to model solids friction through horizontal straight pipes, relatively less work has been carried out towards understanding the flow phenomenon around bends. Some models include that of Schuchart (1968), Singh and Wolf (1972), Rossetti (1983), Chamber and Marcus (1986), Bradley and Mills (1988), Pan(1992), Pan and Wypych (1998) and Das and Meloy (2002). Most of the models on bend losses are related to the specific product and laboratory conditions, e.g. location and orientation of the test bend, specific flow conditions etc. Schuchart (1968) was one of the first researchers to study the gas-solids flow through pipe bends. Bradley and Mills (1988) proposed that a more accurate prediction of the overall pressure loss can be achieved by predicting the pressure drop through the straight pipes and bends separately because upon exit from a bend, velocity of solid reduces significantly, due to which solids drop out from the gas stream and would then try to re-accelerate to be again in flow. This re-acceleration of particles causes pressure drop of the gas. Bradley (1990) conducted experiments on the bend pressure drop with test setup similar to that presented by Bradley (1989) using wheat flour and with seven different types of bends. It was concluded that different radius bends produce similar loss (i.e. pressure drop is irrespective of the radius of curvature of the bends), but this result contradicts with the findings of Mills and Mason (1985).Chaudhry et al. (2001) did experiments on 10 materials using the setup, which was referred by Bradley (1989) and developed a model having 50\% accuracy in prediction of bend pressure drop.All these existing models are empirical and have shown reliable results for total pipeline pressure drop when applied to the researchers own data, but have not been 
adequately examined for accuracy and reliability for different products and set up conditions. The aim of the present paper is to investigate into the effects of different bend models on the prediction of total pipeline pneumatic conveying characteristics for different pipelines.

\section{Experimental Setup}

Power plant fly ash was conveyed from fluidized dense- to dilute-phase through pipelines of different lengths and diameters (i.e. 69 mm I.D. x 168 m long, 105 mm I.D. x 168 m long, 69 mm I.D. x $554 \mathrm{~m}$ long pipelines). Physical properties of fly ash and pipeline conditions are given in Table 1. Tests were conducted for different air and solid mass flow rates (air flow rate: 0.02 to $0.3 \mathrm{~kg} / \mathrm{s}$ and solid flow rate: 2 to $8 \mathrm{~kg} / \mathrm{s}$ ).

Table 1: Physical properties of fly ash

\begin{tabular}{|c|c|c|c|c|c|c|c|c|c|}
\hline Product & $\begin{array}{l}d_{10} \\
(\mu \mathrm{m})\end{array}$ & $\begin{array}{l}d_{50} \\
(\mu \mathrm{m})\end{array}$ & $\begin{array}{l}d_{90} \\
(\mu \mathrm{m})\end{array}$ & $\begin{array}{l}\text { Range } \\
(\mu \mathrm{m})\end{array}$ & $\begin{array}{l}\rho_{\mathrm{s}} \\
\left(\mathrm{kg} / \mathrm{m}^{3}\right)\end{array}$ & $\begin{array}{l}\rho_{\text {bl }} \\
\left(\mathrm{kg} / \mathrm{m}^{3}\right)\end{array}$ & $\begin{array}{l}\text { Blow } \\
\text { Tank }\end{array}$ & $\begin{array}{l}\text { D } \\
(\mathrm{mm})\end{array}$ & $\begin{array}{l}\text { L } \\
\text { (m) }\end{array}$ \\
\hline Fly ash & 2 & 30 & 110 & $1-500$ & 2300 & 700 & $\mathrm{BD}$ & $\begin{array}{l}69 \\
105 \\
69\end{array}$ & $\begin{array}{r}168 \\
168 \\
554\end{array}$ \\
\hline
\end{tabular}

The schematic of $69 \mathrm{~mm}$ I.D. x $168 \mathrm{~m}$ long pipeline is shown in Figure 1 and the schematic for the larger and longer pipeline are shown in Annexure: Figure A1 and Figure A2, respectively. The set up comprised of $0.5 \mathrm{~m}^{3}$ bottom- discharge type blow tank feeding system. Single and twin blow tanks were used for $168 \mathrm{~m}$ and $554 \mathrm{~m}$ long pipes, respectively. Pipes and bends used in the experiments were made of mild steel. 


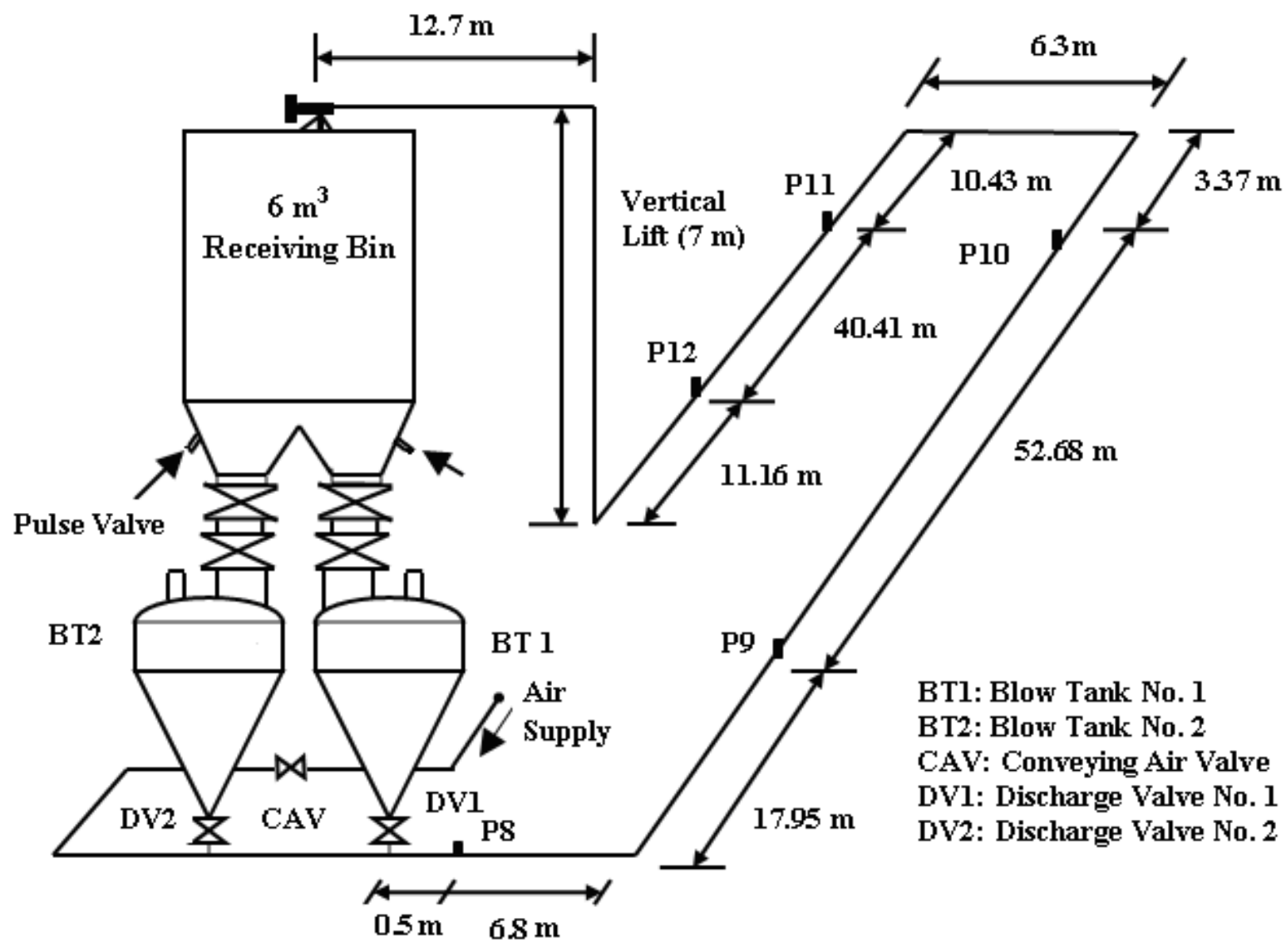

Fig.1. Layout of the 69 mm I.D. x 168 m Test Rig (for fly ash)

The $168 \mathrm{~m}$ long pipeline consisted of 5 bends (2 closely coupled) and a vertical lift of $7 \mathrm{~m}$ height, while the554 m long pipeline had17 bends (8 closely coupled) and a vertical lift of the same elevation. All bends had $1 \mathrm{~m}$ radius of curvature and $90^{\circ}$ bend angle. Compressed air at maximum pressure of approximately $800 \mathrm{kPa}$ was supplied from Ingersoll Rand dieselpowered Model P375-WP, $10.6 \mathrm{~m}^{3} / \mathrm{min}$ free air delivery screw compressor. Five static pressure transducers were used in the system (P8-P12) to measure static pressure in horizontal straight pipes. These were installed in a way that were unaffected by any bend effects.P8 was used to measure the total pipeline pressure drop while P9-P12 measured the static pressures along the pipe. Output data from P9-P12 were used to model solid friction factor of straight horizontal pipe. Specification of static pressure transducers: manufacturer: 
Endress and Hauser, model: Cerabar PMC133, pressure range: 0-6 and 0-2 bar, maximum pressure: 40 bar (absolute), current signal: 4-20 mA. Receiver bin of capacity $6 \mathrm{~m}^{3}$ was installed with pulse-jet type dust filter. All other required instruments, such as PRV (pressure reducing valve), flow meter, NRV (non-return valve), blow valve, pressure gauge and load cells (shear beam type) were suitably placed. Calibration of the transducer, load cells and flow meter were performed using the standardized calibration procedure (Pan, 1992). To record the electrical output signals from the load cells, pressure transducer and flow meters, a portable PC compatible data logger (Datataker 800 of Data electronics) was used, having 24 channels. Figures 2 to 4 show the experimental data points of fly ash conveyed through three pipelines (69 mm I.D. × $168 \mathrm{~m}$ long, $105 \mathrm{~mm}$ I.D. $\times 168 \mathrm{~m}$ long and $69 \mathrm{~mm}$ I.D. $\times 554 \mathrm{~m}$ long pipes). Pneumatic conveying characteristics have been drawn from the experimental data points using an interpolation technique (Mallick, 2010). Lines of constant Froude number at pipe inlet $\left(\mathrm{Fr}_{\mathrm{i}}\right)$ indicate blockage or unstable conveying boundary. Mean Froude number $\left(\mathrm{Fr}_{\mathrm{m}}\right)$ lines indicate the location of the pressure minimum curves. 


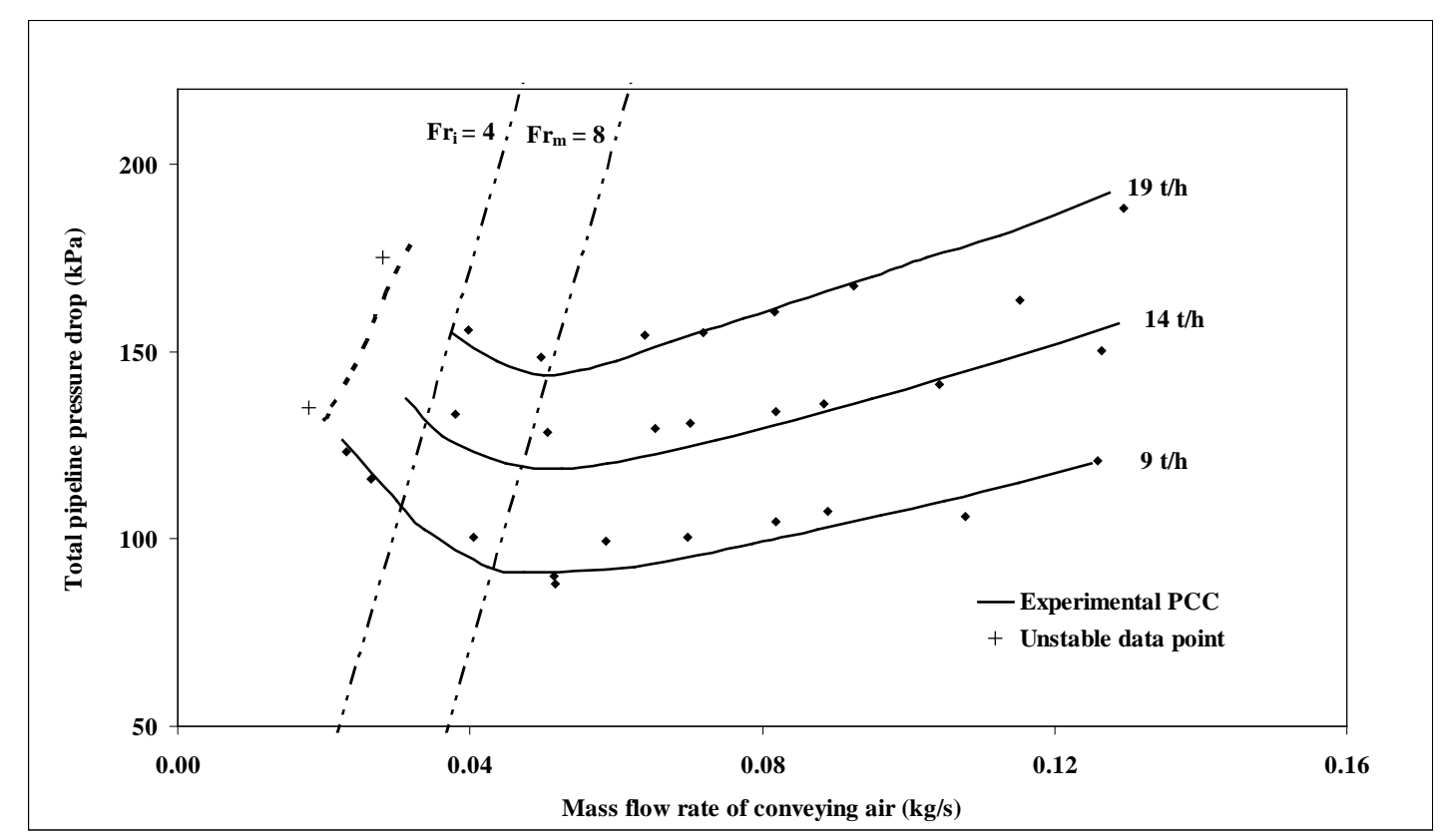

Fig. 2. PCC for total pipeline pressure loss for fly ash and $69 \mathrm{~mm}$ I.D. $\times 168 \mathrm{~m}$ long pipe

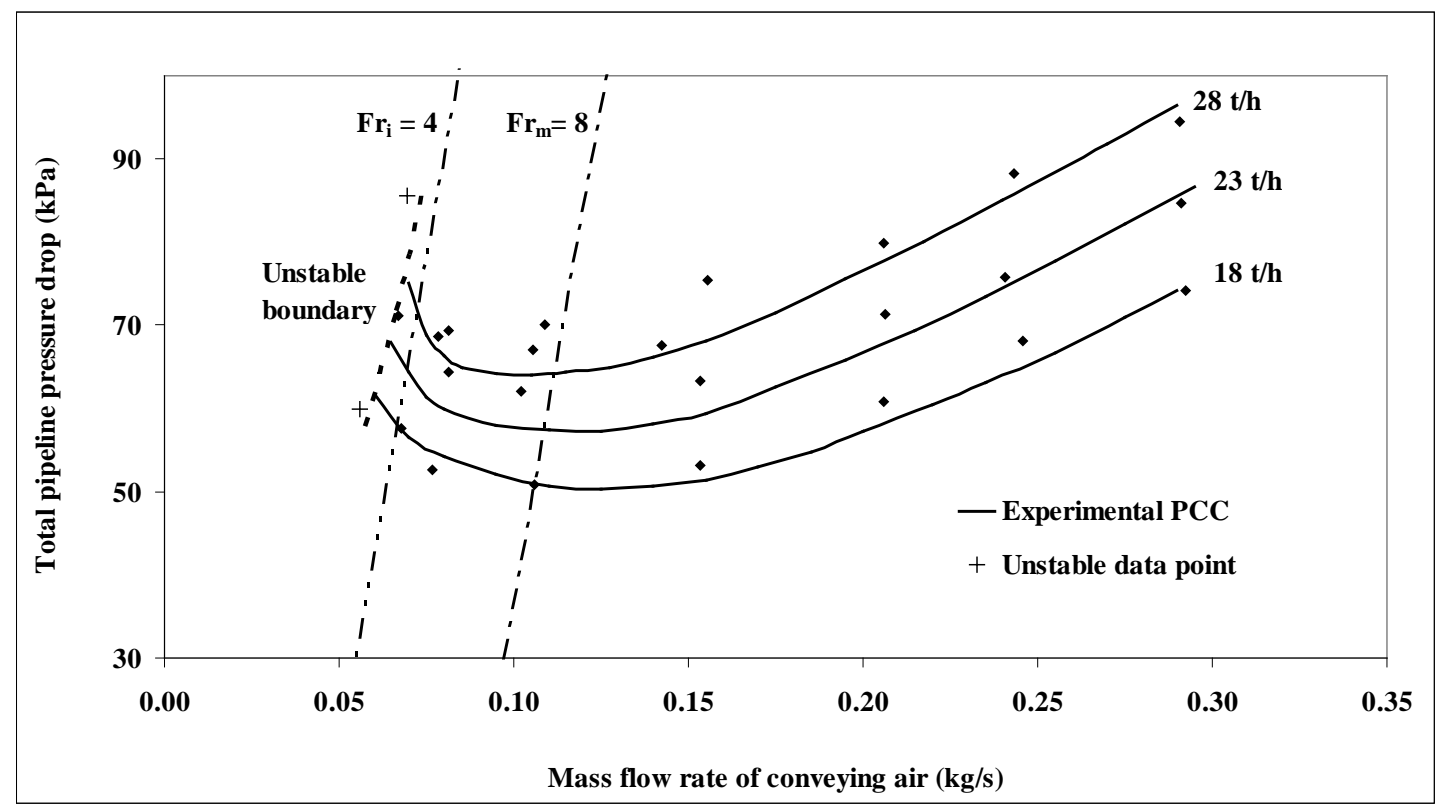

Fig. 3. PCC for total pipeline pressure loss for fly ash and $105 \mathrm{~mm}$ I.D. $\times 168 \mathrm{~m}$ long pipe 


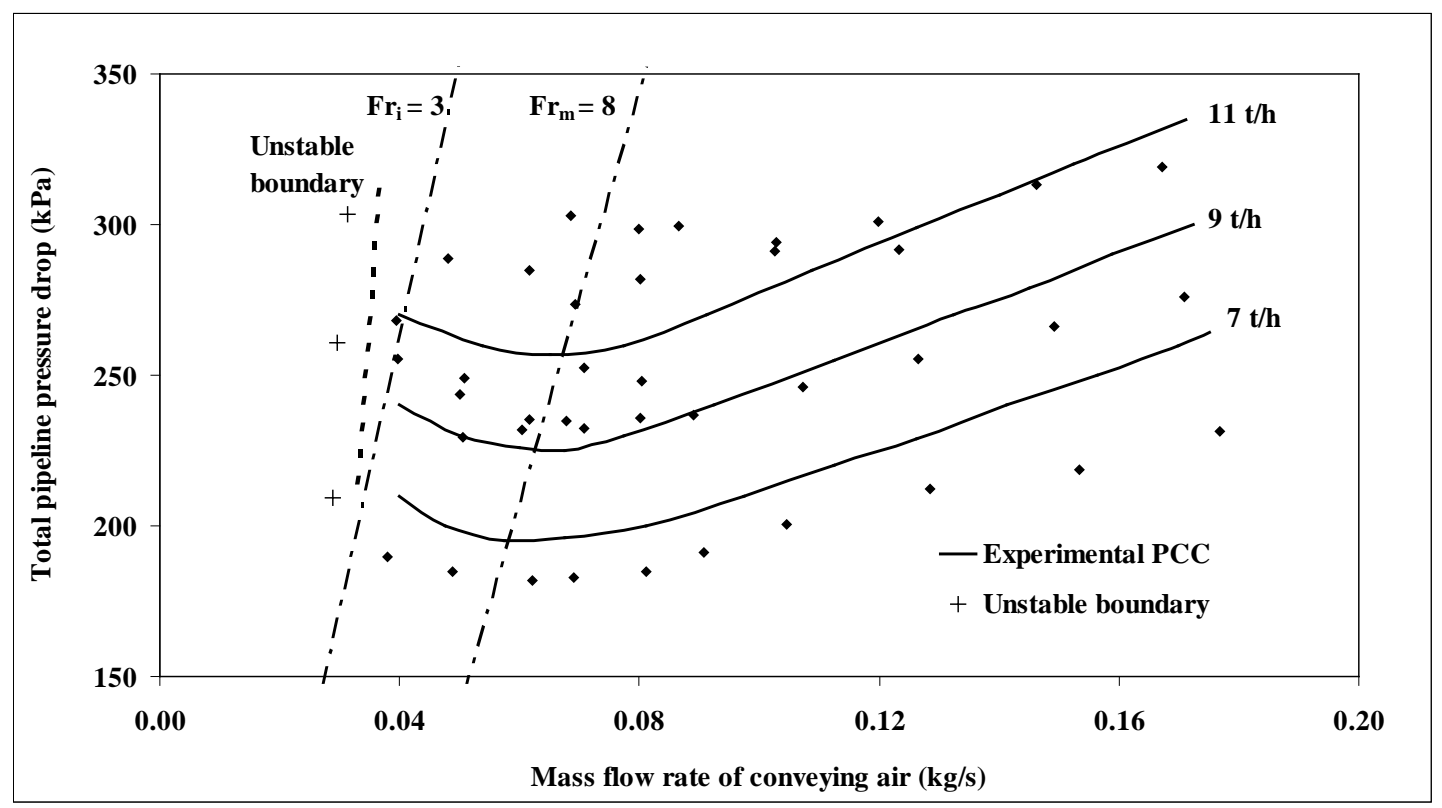

Fig. 4. PCC for total pipeline pressure loss for fly ash and $69 \mathrm{~mm}$ I.D. $\times 554 \mathrm{~m}$ long pipe

\section{Models to predict bend pressure drop}

Schuchart (1968) used number of bends (radius of curvature: $60 \mathrm{~mm}$ to $350 \mathrm{~mm}$; pipe I.D: $34.35 \mathrm{~mm}$ ) to convey: quartz beads ( $\mathrm{d}_{\mathrm{p}}$ : 1490, 1850, 2350 and $2960 \square \mathrm{m} ; \square ; 2610 \mathrm{~kg} / \mathrm{m}^{3}$ ) and polyamide plastic $\left(\mathrm{d}_{\mathrm{p}}: 2180 \square \mathrm{m} ; \square: 1140 \mathrm{~kg} / \mathrm{m}^{3}\right)$. Volumetric concentrations during flow were limited up to only 5\%, thus indicating dilute-phase flow. The solids contribution of the pressure drop due to the solids-gas flow through bends was expressed as:

$\left(\frac{\Delta p_{\text {bend }}}{\Delta p_{z}}\right)_{\text {solids }}=210\left(\frac{2 R_{B}}{D}\right)^{-1.15}$

Where, $\left(\Delta \mathrm{p}_{z}\right)_{\text {solids }}$ is the pressure drop due to the solids for an equivalent length of straight pipe(having the same arc length as that of the bend). This is to be obtained using solid friction factor model (for straight pipe). Finally, the total loss through the bend is to be calculated by 
adding the pressure drop due gas-only friction term with $\left(\Delta \mathrm{p}_{\mathrm{z}}\right)_{\text {solids. }}$ Schuchart (1968) mentioned that for pressure drop calculation of straight pipe due to solids only, Barth (1958) equation (1) and for gas only pressure drop, Ito’s (1959) expression (4) is to be used. It has been considered that Barth (1958) expression would be valid for dense-phase mode, whereas it is believed that the Barth (1958) model was originally proposed for coarse particles in dilute-phase flow. However, several researchers such as Pan (1992), Pan and Wypych (1998) and Mallick (2010) have used this model for fine powders conveying in dense-phase. Hence, this model has been evaluated for the fluidized dense-phase conveying of fine powders in the present paper. It is to be noted that the equation (2) includes the $\left(\Delta \mathrm{p}_{\mathrm{z}}\right)_{\text {solids }}$ term. Therefore, there liability of Schuchart (1968) bend model would depend on the accuracy of modelling solids friction through straight pipes, which in itself is an area of active research (Mallick, 2010).

$\left(\Delta p_{\text {bend }}\right)_{\text {air }}=\left(\frac{0.029+0.304\left[\operatorname{Re}\left(r / R_{B}\right)^{2}\right]^{-0.25}}{\left(R_{B} / r\right)^{\frac{1}{2}}}\right) \frac{L \rho_{o} V_{O}^{2}}{2 D}$

Total bend pressure drop due to bend: $\Delta p_{\text {bo }}=\left(\Delta p_{\text {bend }}\right)_{\text {solid }}+\left(\Delta p_{\text {bend }}\right)_{\text {air }}$

Singh and Wolf (1972) performed 108 number of experiments on 3 bends (radius of curvature: 381, 762 and $1220 \mathrm{~mm}$; pipeI.D: 150mm) by using granular chopped forged as the conveying material. Using non-dimensional approach, in following grouping were arrived at:

$\frac{\Delta p_{b s}}{\rho_{f o} V_{f o}^{2}}=f\left(\frac{R}{D}, \frac{m_{s}}{\rho_{f o} V_{f o} D^{2}}, \beta_{a}\right)$

Where, $\beta_{\mathrm{a}}$ is bend angle. It was assumed that a generalised power function law would be valid; a relationship was developed between $\frac{\Delta p_{b s}}{\rho_{f o} V_{f o}^{2}}$ and $\frac{m_{s}}{\rho_{f o} V_{f o} D^{2}}$, resulting in the following model for bend pressure drop: 
$\Delta p_{b 0}=a_{c}+a_{s} \frac{m_{s} \cdot V_{o}}{D^{2}}\left(\frac{R}{D}\right)^{a_{b}}$

Where, $\mathrm{a}_{\mathrm{c}}$ is the bend loss due to air only. Using least square method and large number of experimental data, the following expression was obtained:

$\Delta p_{b 0}=0.13+a_{s} \frac{m_{s} \cdot V_{o}}{D^{2}}\left(\frac{R}{D}\right)^{-0.18}$

For bend angles of $45^{\circ}$ and $90^{\circ}$, the values of $a_{s}$ were found to be 0.00334 and 0.00537 , respectively. The model assumes that the bend pressure drop decreases with increase in the radius of curvature of bend, although increase in radius of curvature implies the powders would need to traverse along a longer curvilinear path through the bend (hence, higher amount of particle to wall friction). The model considers the importance of gas velocity at the exit to the bend (indicting the contribution of the particle reacceleration phenomenon at bend outlet as an important contributor of bend loss).

Rossetti (1983) performed experiments using coarse and fine particles for different bends (pipe diameter to bend diameter ratio 2 to 8.4) and gave equation (9) for bend pressure loss. Coarse particles tend to lose energy through wall collisions, resulting in re-acceleration energy loss (Pan, 1992).

$$
\Delta p_{b o}=\left(\lambda_{f}+\lambda_{s}\right) \frac{\rho_{o} V_{o}^{2}}{2}
$$

The primary contributor to bend loss is believed to be due to re acceleration of particles at the outlet to the bends (Pan, 1992). Re-acceleration loss takes place at the outlet of the bends. Hence, in this equation (8), the use of bend outlet conditions (such as gas density and velocity 
at outlet of the bend) appear justified. Westman et al. (1987) suggested following correlations of $\lambda_{\mathrm{f}}$ and $\lambda_{\mathrm{s}}$. This model has also assumed that condition at the exit to the bend is more important due to the slowing down of particles at the outlet of bends (because of particle friction against the bend wall) and the subsequent energy requirement to reaccelerate the particles.

$$
\begin{aligned}
& \lambda_{f}=0.167\left[1+17.062\left(\frac{2 R_{B}}{D}\right)^{-1.219}\right] R e^{-0.17}\left(\frac{2 R_{B}}{D}\right)^{0.84} \\
& \lambda_{s}=\frac{5.4 m^{* 1.293}}{F r_{o}^{0.84}\left(\frac{2 R_{B}}{D}\right)^{0.39}}
\end{aligned}
$$

Chamber and Marcus (1986) provided expression (11) for total bend pressure loss in the conveying pipeline. This expression (11) was used by Jones and Williams (2003), Williams and Jones (2004) in the back calculation method of deriving an expression for the solid friction factor for straight pipe length. This model does not take into account particle properties, location of bends, etc. The value of bend loss factor (accounting for the radius of curvature of bends) has been considered as 0.5 (Mallick, 2010). The air density and velocity have been considered corresponding to the bend outlet conditions. Considering the popularity of this model (Mallick, 2010), the same has been evaluated in the present study.

$$
\Delta p_{b o}=N B\left(1+m^{*}\right) \frac{\rho V^{2}}{2}
$$

Bradley (1989) did experiments using fly ash and wheat flour for pipeline of I.D: 50, 75 and $100 \mathrm{~mm}$ and 7 types of bends of different radius of curvature. A wide range of conveying conditions were employed; flow velocity varied from 4 to $45 \mathrm{~m} / \mathrm{sec}$ and solid loading ratio was up to 130. He proposed the following format (equation 12): 
$\Delta p_{b}=1 / 2 K_{b} \rho_{\text {sus }} V^{2}$

In the earlier work of Westman et al. (1987), a mass loading ratio (m*)was used to model solids friction through the bends. However, Bradley (1989) questioned the applicability of using a mass ratio term. According to Bradley (1989), instead of mass ratio, solids volume occupancy (similar to the volumetric concentration in pipeline) is more important for accurate description of the flow phenomenon. According to him, it is the inter-particulate gaps through which the air has to travel and the air creates a slip for the solids to be dragged in the direction of flow. Therefore, a volumetric term (such as suspension density) has been considered to be more reliable in describing the dense-phase flow conditions. The velocity term in the above equation is believed to be representing suspension or non-suspension condition of flow. Bradly (1989) expressed $\mathrm{K}_{\mathrm{b}}$ as a function of suspension density. A review of Bradley (1989) by Pan (1992) mentioned that the pressure drop caused by bend is the sum of two components. One component of the loss happens in the bend itself and other component occurs in the straight section of pipe just after the bend (due to the re-acceleration of the particles).

Pan (1992) evaluated Bradley (1989) slope concept of bend loss estimation, in which pressure drop due to bend could be calculated by the difference profiles of pressure transducer values (before and after the bend). Pan (1992) argued that a small fluctuation in measured static pressure is expected to create a great influence on the value of estimated bend pressure drop, e.g. $\pm 1.81 \%$ change in static pressure can result in a $\pm 62.8 \%$ change in bend pressure drop. Pan (1992) performed experiments on five type of bends: one blind Tee and four radius bends and used fly ash as the conveying material with properties: $\square: 634 \mathrm{~kg} / \mathrm{m}^{3}$; $\square: 2197 \mathrm{~kg} / \mathrm{m}^{3}$; 
mean $\mathrm{d}_{\mathrm{p}}$ : $15.5 \square \mathrm{m}$. Based on mathematical and dimensional analysis, semi-empirical correlation (14) was derived to predict the solids friction factor through bends:

$$
\begin{aligned}
& \Delta p_{b o}=m^{*} \lambda_{s} \frac{\rho_{o} V_{o}^{2}}{2} \\
& \lambda_{s}=Y_{1} m^{* Y_{2}} \mathrm{Fr}_{o}^{Y_{3}}
\end{aligned}
$$

Values of the exponents $Y_{1}, Y_{2}$ and $Y_{3}$ (equation 14) were determined by minimising the sum of squared errors of pressure along the downstream pipe because the bend outlet conditions are the effective for the major portion of bend loss. Based on his empirical data, Pan (1992) proposed the value of $\mathrm{Y}_{1}, \mathrm{Y}_{2}$ and $\mathrm{Y}_{3}$ (for $90^{\circ}$ bend angle) as $0.0052,0.49$ and 1.1182 respectively.

Pan and Wypych (1998) did experiments with four samples of fly ash having properties: particle size: 3.5 to $58 \square \mathrm{m}$; particle density: 2180 to $2540 \mathrm{~kg} / \mathrm{m}^{3}$; loose poured bulk density: 634 to $955 \mathrm{~kg} / \mathrm{m}^{3}$; velocity range: 3 to $25 \mathrm{~m} / \mathrm{s}$; solid loading ratio up to 130 . They derived bend loss expression (15) due to solids only. Both Pan (1992) and Pan and Wypych (1998) have considered that the bend outlet conditions are more important to represent the losses through the bends.

$\Delta p_{b s}=0.5 m^{*} \lambda_{b s} \rho_{b o} V_{b o}^{2}$

Where $\lambda_{b s}=0.0097 m^{* 0.5676} \mathrm{Fr}_{o}{ }^{0.9647} \rho_{o}^{-0.6232}$

Das and Meloy (2002) performed tests with a pipeline of 63.5 mm I.D. x 169.8 m long, with six samples of fly ash and compared the pressure drop across close-coupled to isolated $90^{\circ}$ 
bends. Six ash samples of different properties were used in the test. The following correlation (18) was derived for the purpose of comparison between the single and close-coupled bends:

$\frac{\Delta p_{\text {solids }}}{m^{*}}=X_{1} V_{o}^{X_{2}}$

Where, $\mathrm{X}_{1}$ and $\mathrm{X}_{2}$ are constants specified for a particular ash and bend geometry. For single

(isolated) bends and certain type of fly ash, value of $\mathrm{X}_{1}$ and $\mathrm{X}_{2}$ was $0.3 \times 10^{-7}$ and 3.4 respectively and for double (close-coupled) bends value of $X_{1}$ and $X_{2}$ was $2.2 \times 10^{-7}$ and 3.0 respectively. This model does not consider a separate solids friction factor term for bends (as used by Pan, 1992 and Pan and Wypych, 1998) and have considered the solids contribution to bend loss is a linear function of solids loading ratio.

\section{Model for solid friction factor for horizontal straight pipe}

For the evaluation of bends models using total pipeline pneumatic conveying characteristics (PCC), straight pipe pressure drop are to be first calculated and then are to be added to the bend pressure drop calculated by different bend models. For the purpose of solid fiction factor modelling for straight pipes, following general power function format (18) was employed. This format has been previously used by other researchers, such as Pan and Wypych (1998), Jones and Williams (2003) and Williams and Jones (2004).

$\lambda_{s}=K\left(m^{*}\right)^{a}(F r)^{b}$ 
Using static pressure data obtained from straight pipe points (P9-P10) across straight horizontal pipe section of length $52.68 \mathrm{~m}$ for a wide range of conveying data from dense to dilute-phase, following power function correlation (19) for solid friction factor has been derived using least square method. The high value of $\mathrm{R}^{2}$ suggests that the model of solid fiction factor is a good fit with experimental data.

$\lambda_{s}=20.807\left(m^{*}\right)^{-0.71}\left(F r_{m}\right)^{-2.1131} \quad\left[\mathrm{R}^{2}=0.998\right]$

\section{Evaluation of bend models}

The effects of selecting different bend models on the prediction of total pipeline pressure drop conveying characteristics were evaluated by estimating the total pipeline conveying characteristics for fly ash for different solids flow rates for the three test rigs(69 mm I.D. $\mathrm{x}$ $168 \mathrm{~m}$ long, 105 mm I.D. x $168 \mathrm{~m}$ long,69 mm I.D. x 554 m long pipelines) by using each of seven bend models (equation: 2, 7, 8, 11, 13, 15, 17) and comparing the predicted PCC against experimental data. This model (equation 19) was used to calculate the pressure drop in straight pipe lengths. In all losses, losses due to initial acceleration and verticals were calculated as per Marcus et al. (1990). As the same set of models were used to estimate pressure drop in horizontal pipes, vertical and for initial acceleration, therefore any variation in magnitude (and trend) of the predicted total pipeline conveying characteristics should have occurred only due to the difference in selection of bend models. Results are shown in Figure 5 to 7. 


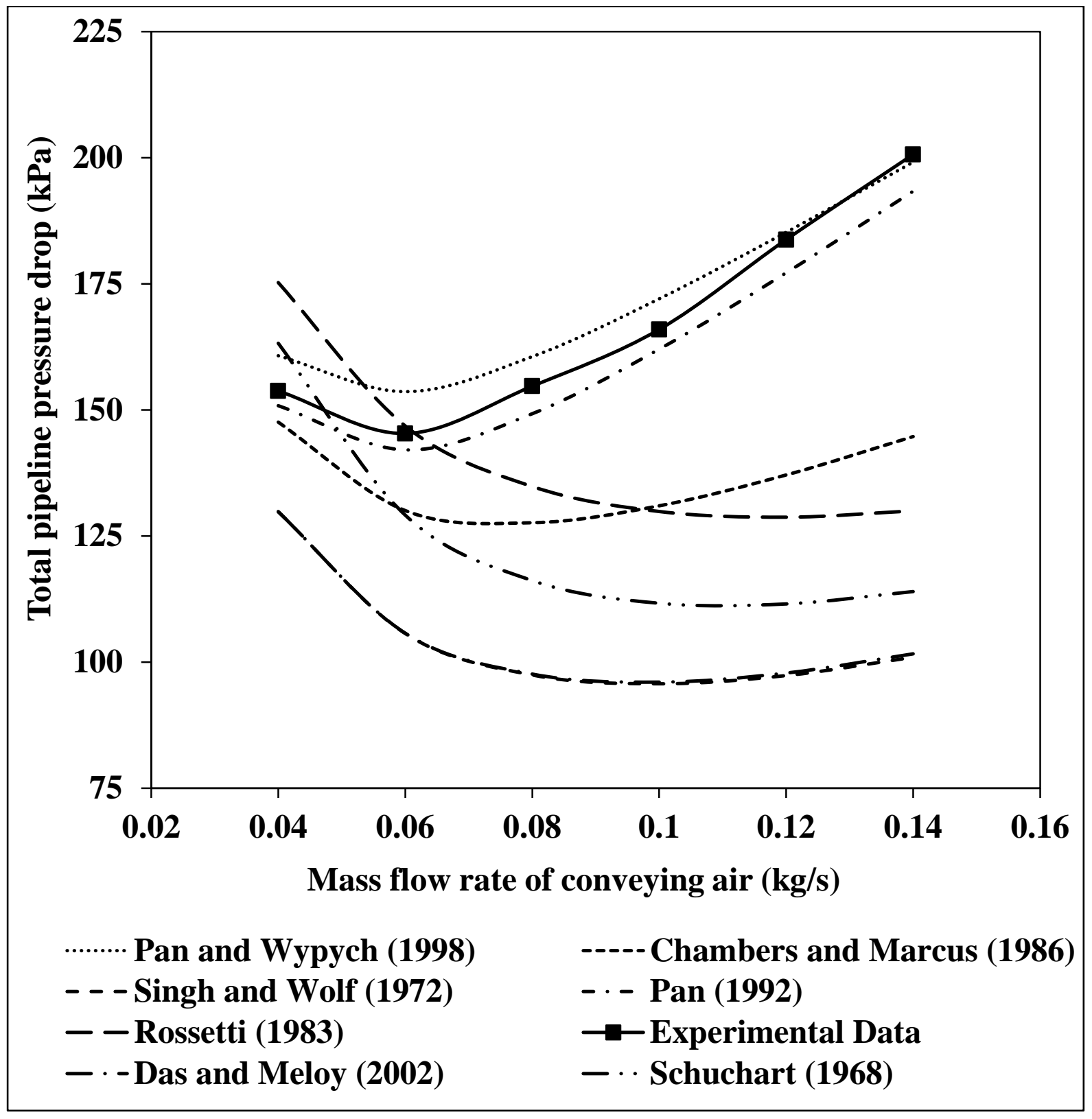

Fig. 5. Comparison of experimental versus predicted values of total pipeline pressure drop (fly ash, $\mathrm{D}=69 \mathrm{~mm}, \mathrm{~L}=168 \mathrm{~m}, \mathrm{~m}_{\mathrm{s}}=19 \mathrm{t} / \mathrm{h}$ ) 


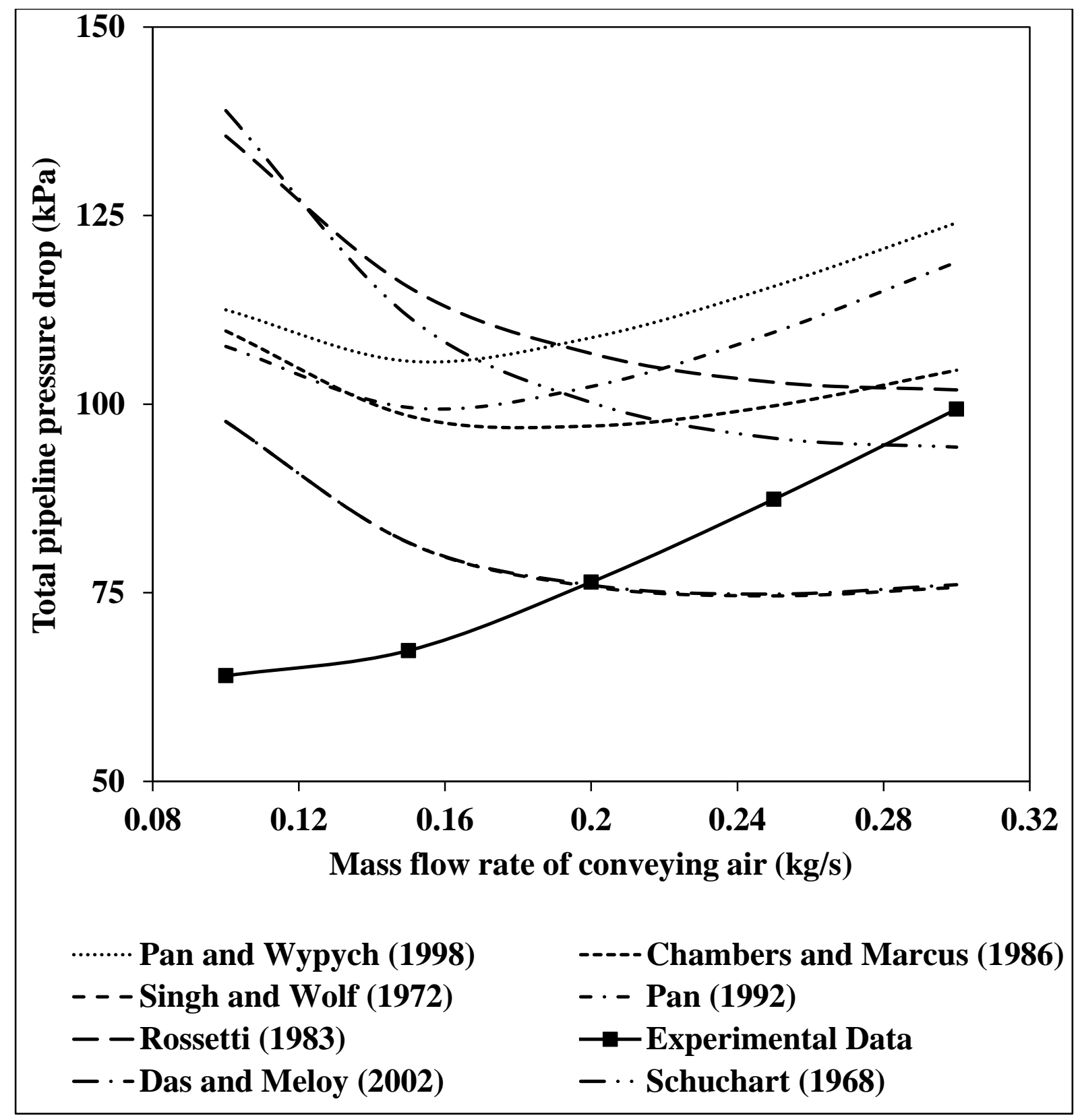

Fig. 6.Comparison of experimental versus predicted values of total pipeline pressure drop (fly ash, D = 105 mm, L = $168 \mathrm{~m}, \mathrm{~m}_{\mathrm{s}}=28 \mathrm{t} / \mathrm{h}$ ) 


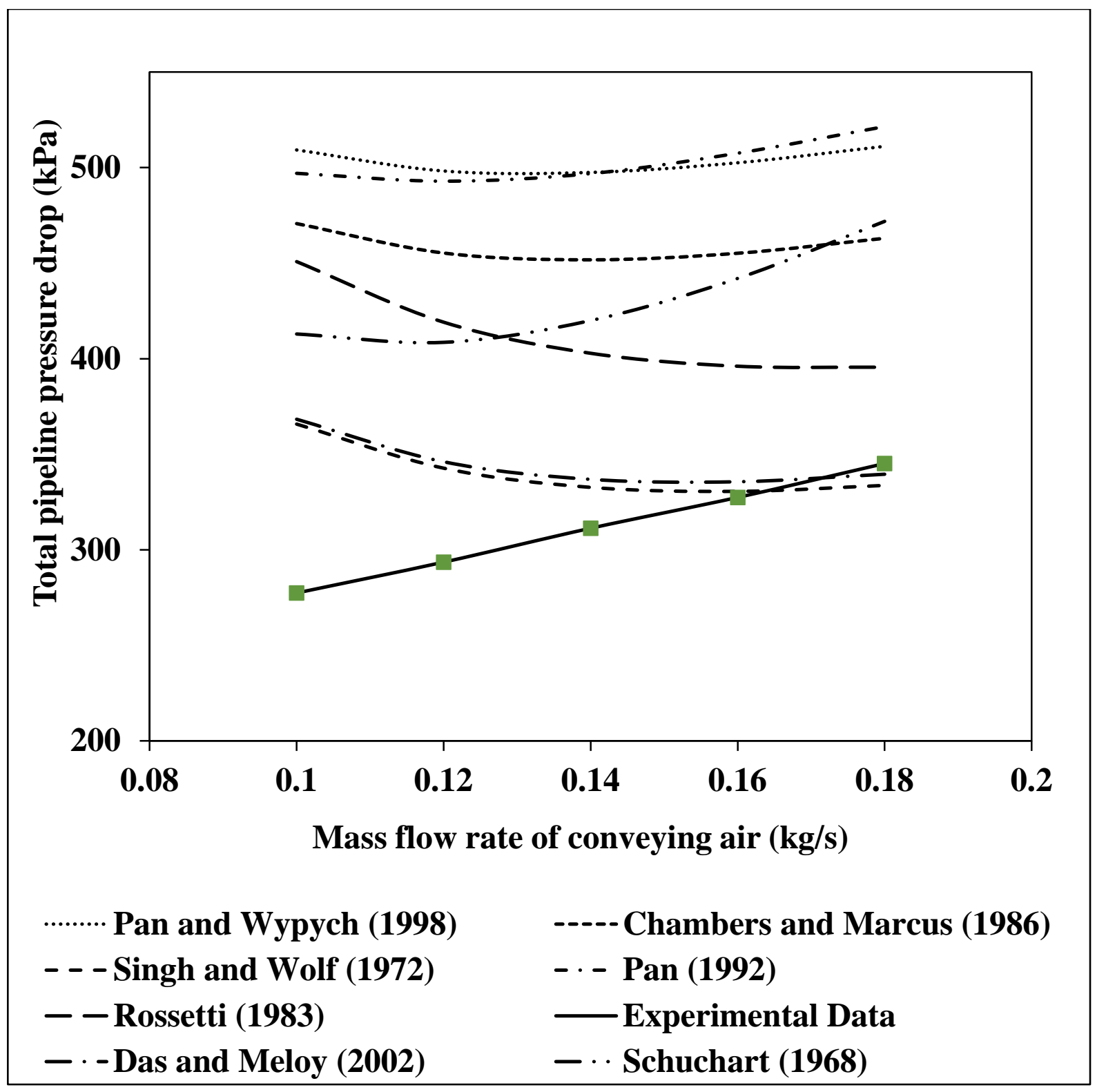

Fig. 7.Comparison of experimental versus predicted values of total pipeline pressure drop (fly ash, $\mathrm{D}=69 \mathrm{~mm}, \mathrm{~L}=554 \mathrm{~m}, \mathrm{~m}_{\mathrm{s}}=11 \mathrm{t} / \mathrm{h}$ )

The above results in Figure 5 to 7 showed that the selection of different bend models can generate significantly different predicted total pipeline conveying characteristics (even though the same solids friction factor model was used to calculate pressure drop in straight horizontal pipeline). Figure 5 (69 mm I.D x $168 \mathrm{~m}$ long)showed that in the predicted total pipeline PCC, predictions using Chamber and Marcus (1986), Pan (1992) and Pan and Wypych (1998) models follow the similar trends as the experimental PCC. Whereas, 
predictions using Rossetti (1983), Schuchart (1968), Singh and Wolf (1972) and Das and Meloy (2002) models follow the reverse trend, i.e. instead of ' $U$ ' shaped PCC, the predicted total pipeline pressure drop values decline with increase in air flows. There was significant difference in prediction of total pipeline conveying characteristics in the dilute phase region between Pan and Wypych (1998) and Das and Meloy (2002). On the other hand, the total pipeline PCC of Pan (1992) and Pan and Wypych (1998) seem to follow the experimental trends much better. However, the model presented by other researchers is shown to underpredict in the dilute-phase region. Figure 6 (larger pipe) shows that the selection of Pan and Wypych (1998) and Das and Meloy (2002) model results in significant differences in total pipeline pressure drop in the dilute phase regime. When the predicted total pipeline PCC were compared with the experimental plots, Pan and Wypych (1998) and Pan (1992) provided over-predictions, whereas Das and Meloy (2002) and Singh and Wolf (1972) resulted in under-predictions. Schuchart (1968),Rossetti (1983) and Chamber and Marcus (1986) provided reliable estimations for dilute phase. From Figure 7, it can be seen that there are significant differences between the predictions from Pan and Wypych (1998) and Das and Meloy (2002) model and the experimental data for total pipeline pressure drop in dilute phase. When compared to the experimental total pipeline PCC, all bend models gave over prediction, except Das and Meloy (2002) and Singh and Wolf (1972) which offered good prediction of pressure drop in dilute phase. Schuchart (1968) model uses a $\Delta \mathrm{p}_{z}$ term (straight pipe pressure drop in the equivalent straight length for the bend). To accurately estimate the values of $\Delta \mathrm{p}_{\mathrm{z}}$, solids friction factor $\left(\lambda_{s}\right)$ needs to be accurately modelled and predicted first. However, modelling of solids friction factor $\left(\lambda_{s}\right)$ on its own is a matter of active research (Mallick, 2010). As the prediction of bend loss depends on the value of calculated $\Delta \mathrm{p}_{z}$ (in turn on the estimated value of $\lambda_{s}$ ), hence any limitation in modelling solids friction factor would also affect the predicted value of bend loss. Also, with increase in air flow rate, the 
value of solids friction factor decreases and subsequently $\Delta \mathrm{p}_{z}$ in the given range of air flow rates. Hence, as per the Schuchart (1968) model given by equation (2), with increase in air velocity, the predicted values of bend pressure loss have decreased, which is in contradiction to the expected experimental trend. Similarly for the Rossetti (1983) model, the estimated values of solids friction factor $\left(\lambda_{s}\right)$ decrease with increase in air flow rates in the range of PCC, which suppresses the predicted bend loss. As a result, the above models (Schuchart, 1968 and Rosetti, 1983) have provided predictions that contradicted the experimental trends. The Singh and Wolf (1972) model was originally developed for granular product and the Das and Meloy (2002) model was developed for closely coupled bends. As a result, these models could not perform well fine powders and for isolated single bends (i.e. bends that are not closely spaced). Prediction of bend only loss for each of seven bend models in $69 \mathrm{~mm}$ I.D. x $168 \mathrm{~m}$ long pipeline, for a range of low velocity (dense-phase) to high velocity flow (dilutephase) regimes are compared in Figure 8 for a constant solid flow rate of fly ash. 


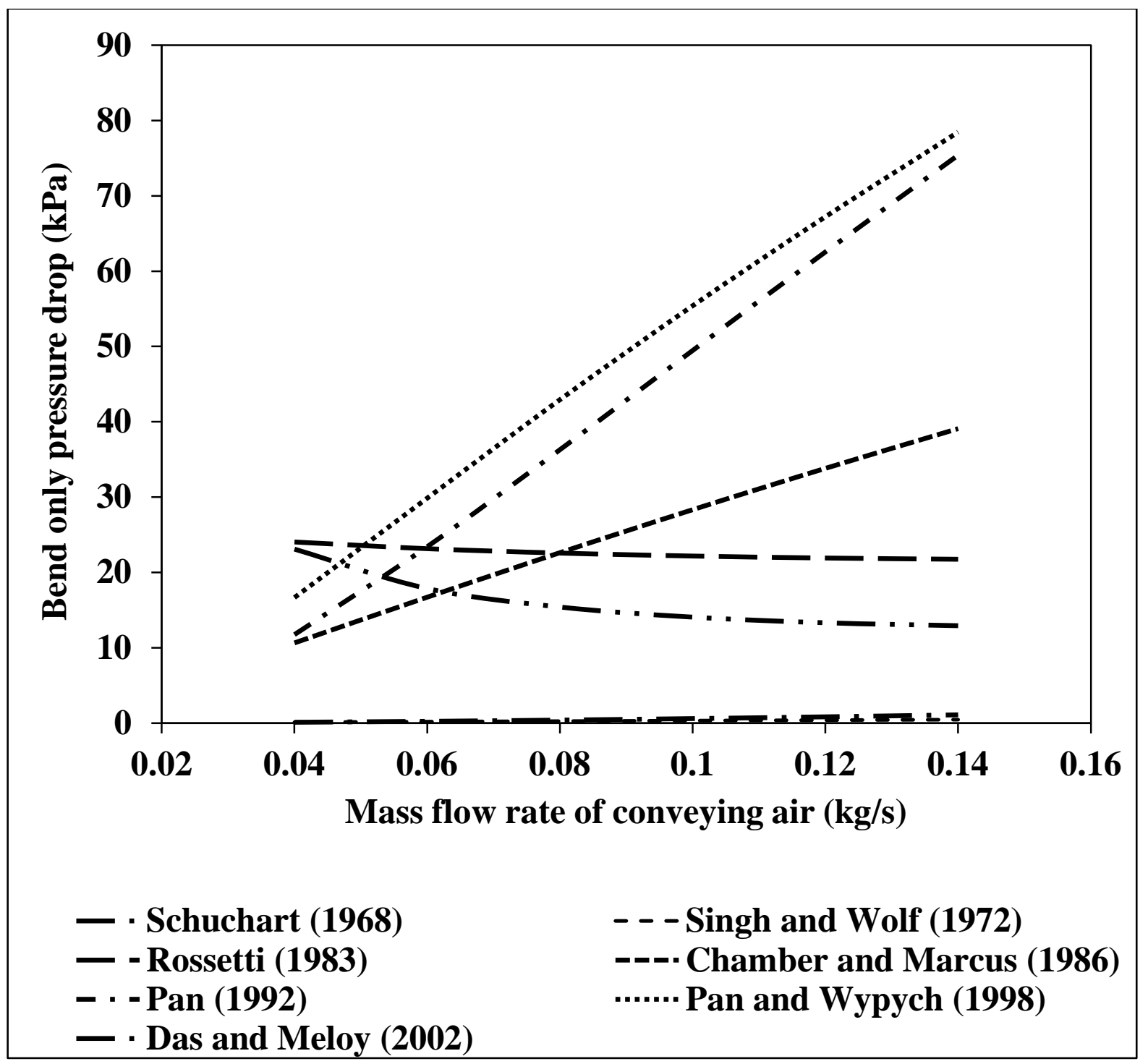

Fig.8. Bend loss PCC based on different bend models in dense to dilute phase

$$
\text { (fly ash, D = } 69 \mathrm{~mm}, \mathrm{~L}=168 \mathrm{~m}, \mathrm{~m}_{\mathrm{s}}=19 \mathrm{t} / \mathrm{h} \text { ) }
$$

Figure 8 shows that different bend models can generate significantly different values of predicted total bend pressure drop (i.e. combined pressure drop caused by all bends in pipeline) both in low and high velocity flow. Singh and Wolf (1972) and Das and Meloy (2002) models are almost superimposing each other and predicted very low values of bend loss (which is incorrect), whereas Chamber and Marcus (1986), Pan (1992) and Pan and Wypych (1998) have shown high pressure loss in dilute-phase as compared to dense -phase regime, which seems to be following the expected trend. The slopesof predictions obtained 
using Pan (1992) and Pan and Wypych (1998) models are very steep. Pressure loss in densephase is more than the dilute phase regime by using Schuchart (1968) model and there is very little change in bend pressure loss due to Rossetti (1983) model in dilute phase as compared to dense phase, which does not follow the expected trend (Pan, 1992). This indicates that Schuchart (1968), Singh and Wolf (1972), Rossetti (1983) and Das and Meloy (2002) are not suitable for the case of fine powder conveying from dense- to dilute-phase flow. This is due to the reduced predicted values of the straight-pipe pressure drop component of Schuchart (1968) model with increase in air flow rates. Also, the estimated values of solids friction factor of Rosetti (1983) model decrease with rise in air flow rates. As a result, these models provide under-prediction in dilute-phase. The prediction capabilities of Singh and Wolf (1972) model and Das and Meloy (2002) are limited as these models were generated empirically from the conveying data of granular materials or for closely coupled bends, respectively. The effect of different bend models on the prediction of total bend loss in the pipeline at a particular air flow rate and solid flow rate were shown in Figure 9 and 10 for the larger and longer pipes, respectively. Predictions have been made at discrete low velocity (dense-phase) and high velocity (dilute-phase) zones. 


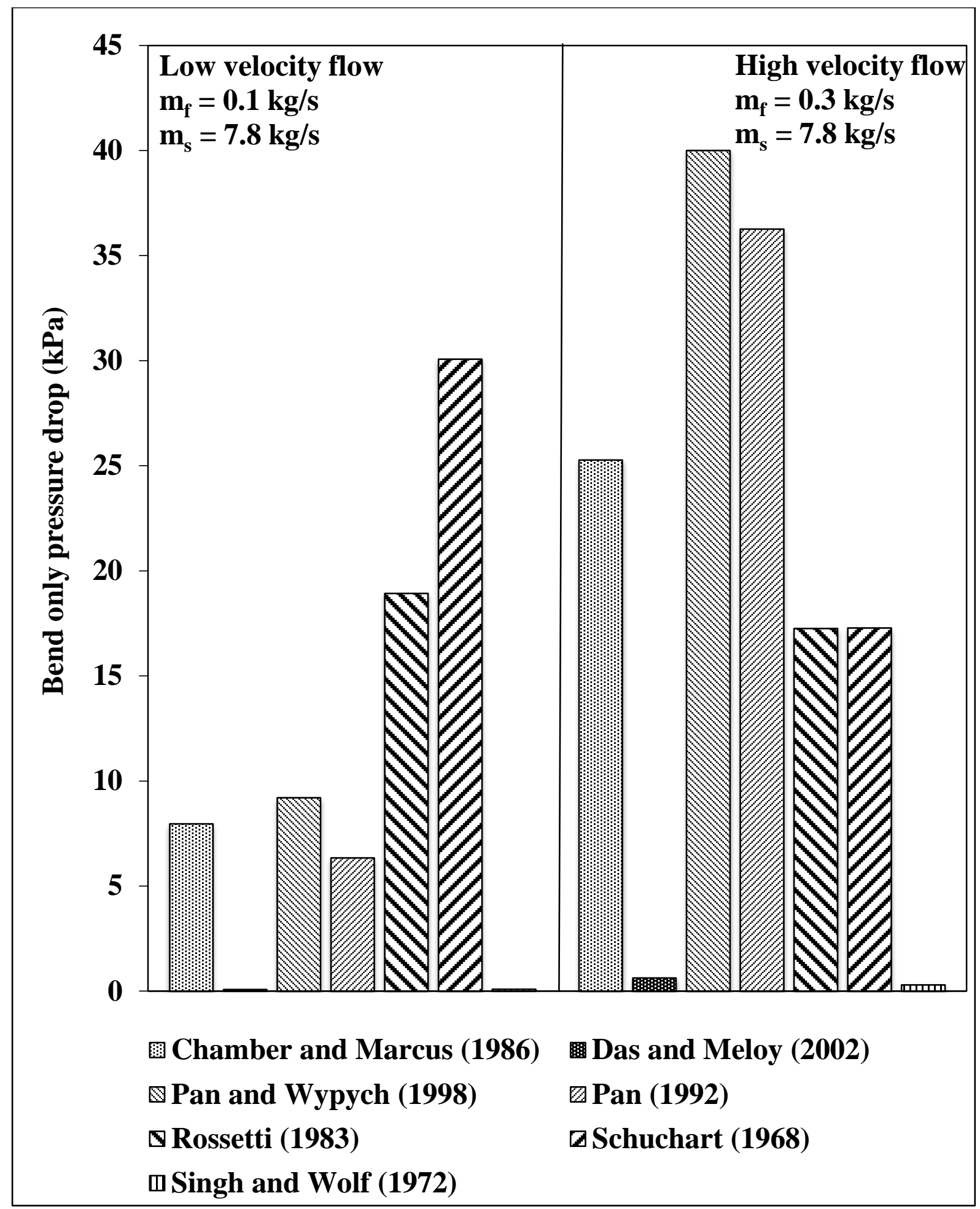

Fig.9.Comparison of bend only pressure drop between low velocity flow and high velocity (fly ash, $\mathrm{D}=105 \mathrm{~mm}, \mathrm{~L}=168 \mathrm{~m}, \mathrm{~m}_{\mathrm{s}}=28 \mathrm{t} / \mathrm{h}$ ) 


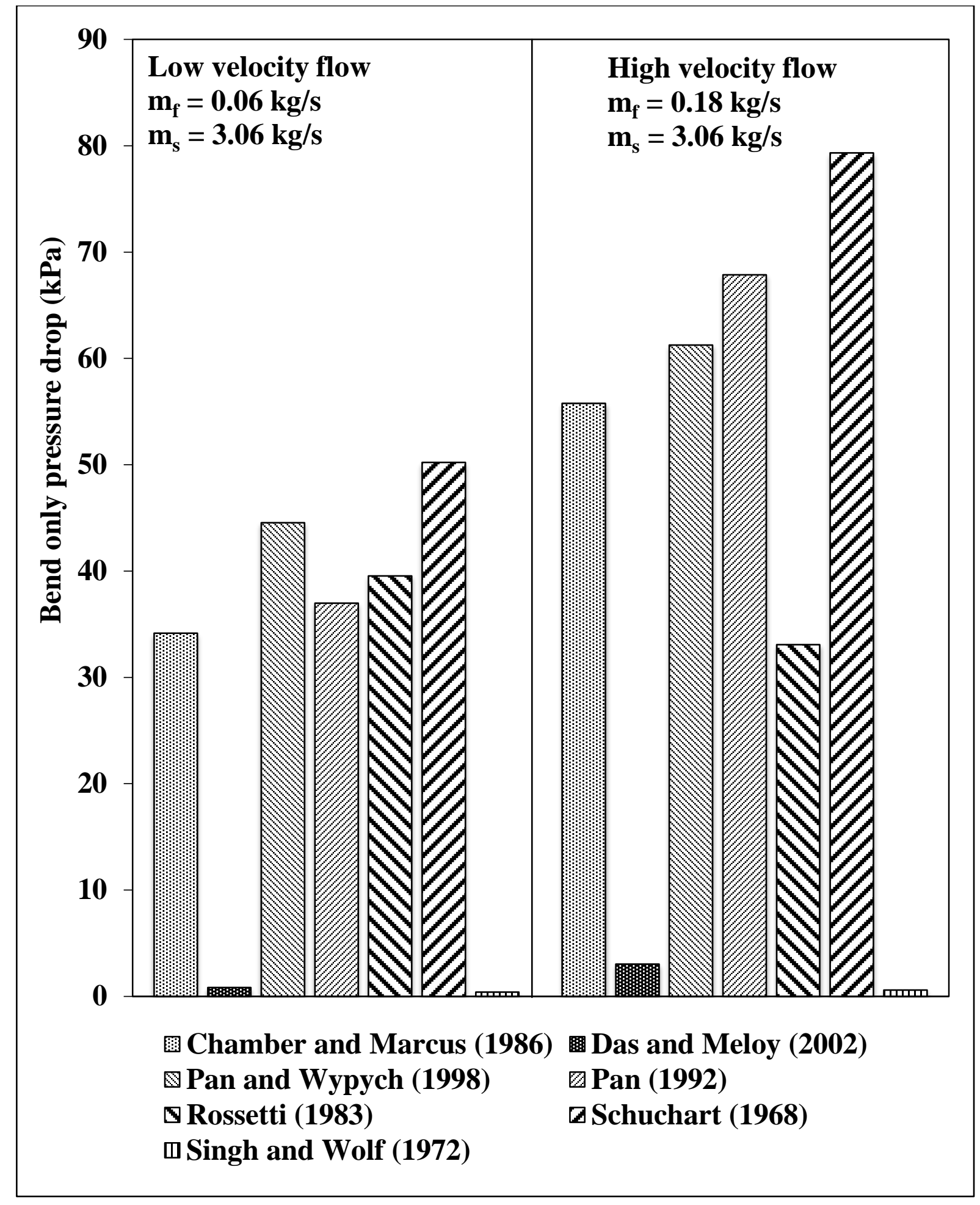

Fig.10. Comparison of bend only pressure drop between low velocity flow and high velocity (fly ash, D = $69 \mathrm{~mm}, \mathrm{~L}=554 \mathrm{~m}, \mathrm{~m}_{\mathrm{s}}=11 \mathrm{t} / \mathrm{h}$ ) 
In Figure 9 and 10, Schuhart (1968), Singh and Wolf (1972) and Das and Meloy (2002) model shows higher predicted bend pressure drop in low velocity range than that at high velocity, as these models over-estimate solids friction in dense-phase. Again, this seems to contradict the general perception of higher bend loss at dilute-phase regime. Predictions using Pan (1992) and Pan and Wypych (1998) bend models seem to follow the expected trends due to the overall dominating effect of positive exponents of gas velocity towards estimation of bend pressure losses (i.e. predicted pressure drops in bend rise with increase in air velocities).

\section{Conclusion}

Seven existing bend models were evaluated for their accuracy and suitability by comparing the predicted bend losses and total pipeline conveying characteristics using different models in various pipelines. Results indicate that the Schuchart (1968) and Rosetti (1983) models provide larger pressure drops in dense-phase compared to the dilute-phase regime, which contradicts the experimental trends. The Singh and Wolf (1972) and Das and Meloy (2002) models provide gross under-predictions. Pan (1992), Pan and Wypych (1998) and Chambers and Marcus (1986) have provided trends of predictions that matched with experimental plots. These models incorporate the gas velocity and density terms corresponding to the bend outlet conditions, which seem to suggest that these models are able to address the momentum loss, roping and reacceleration phenomenon of powder stream at the outlet of bends. Chambers and Marcus (1986) model do not follow the trend of sharp rise in bend loss with increase in air mass flow rates (similar to Pan and Wypych, 1998 and Pan, 1992), but follows a rather steady rise in estimated pressure drop values in dilute-phase (i.e. following a moderate slope). 
Chambers and Marcus (1986) Pan (1992) and pan and Wypych (1998) models are recommended to estimate the bend losses for fly ash conveying systems from dense- to dilute-phase systems. Pan (1992), Pan and Wypych (1998) models could provide some overprediction in dilute-phase zone, but these may be accepted as safety margins in design.

\section{List of Symbols and Abbreviations}

B

$\mathrm{D}$

$\operatorname{Fr}=\mathrm{V} /(\mathrm{gD})^{0.5}$

g

$\mathrm{L}$

$\mathrm{m}_{\mathrm{f}}$

$\mathrm{m}_{\mathrm{s}}$

$\mathrm{m}^{*}=\mathrm{ms} / \mathrm{mf}$

K

$\mathrm{N}$

$\Delta \mathrm{P}$

$\Delta \mathrm{P}_{\text {bo }}$

$\left(\Delta \mathrm{P}_{\mathrm{Z}}\right)_{\text {solid }}$

$\mathrm{R}_{\mathrm{B}}$

r

$\mathrm{Re}=\square \mathrm{VD} / \square$
Bend loss factor

Internal diameter of pipe [m]

Froud number of flow

Acceleration due to gravity $\left[\mathrm{m} / \mathrm{sec}^{2}\right]$

Length of pipe [m]

Mass flow rate of air $[\mathrm{kg} / \mathrm{sec}]$

Mass flow rate of solids [kg/sec]

Solid loading Ratio

Constant of power function

Number of bends

Pressure drop through a straight horizontal pipe [Pa]

Pressure drop through bend $[\mathrm{Pa}]$

Pressure drop due to solids for an equivalent straight length

of the bend $[\mathrm{Pa}]$

Radius of curvature bend [m]

Radius of bend pipe [m]

Reynolds number 
V

Vo

$\rho$

$\rho_{0}$

$\rho_{\mathrm{f}}$

$\rho_{\mathrm{bs}}$

$\rho_{\mathrm{s}}$

$\rho$

Subscripts

b

f

i

o

S

sus

Z

Abbreviations

BD

I.D.

PCC
Superficial air velocity [m/sec]

Velocity at bend outlet $[\mathrm{m} / \mathrm{sec}]$

Density of air $\left[\mathrm{kg} / \mathrm{m}^{3}\right]$

Density of air at bend outlet

Air/gas only friction factor

Solid friction factor at bend

Solid friction factor

Fluid viscosity [Pa.sec]
Bend

Fluid (air)

Inlet condition

Outlet condition

Solids

Suspension

Straight Horizontal Pipe
Bottom Discharge

Internal diameter of pipe

Pneumatic conveying characteristics 


\section{Acknowledgement}

The authors would like to thank Department of Science and Technology, Science and Engineering Research Board, Ministry of Science and Technology (Government of India) for the financial assistance provided under the Young Scientist Scheme No: SR/FTP/ETA$15 / 2011$

\section{References}

Barth, W.(1958).Stromungsvorgangebeim Transport von Festteilchen and Flussigkeitsteilchen in Gasen.Chemie-Ing.-Techn.,30(3),171-180.

Bradley, M. S. A. and Mills, D. (1988). Approaches to dealing with the problem of energy loss due to bends. In the proceedings of $13^{\text {th }}$ Powder and Bulk SolidsConference. 705715.

Bradley, M. S. A. 1989. An improved method of predicting pressure drop along pneumatic conveying pipelines. In the proceedings of $3^{\text {rd }}$ International Conference on Bulk Materials Storage and Transportation, Newcastle, Australia. 282-288.

Bradley, MSA. (1990).Prediction of pressure losses in pneumatic conveying pipelines.Doctoral Dissertation, Thames Polytechnic, London, UK.

Bradley, MSA. (1990).Pressure losses caused by bends in pneumatic conveying pipelines effects of bend geometry and fittings.Powder Handling and Processing, 2, 315-321.

Chambers, A.J., and Marcus, R.D. (1986). Pneumatic conveying calculations. $2^{\text {nd }}$ International Conference on Bulk Materials Storage and Transportation, Wollongong, Australia. 49-52. 
Chaudhry, A.R., Bradley, MSA, Hyder, LM, Reed, AR and Farnish, RJ. (2001). Analysis and modelling of bend pressure losses in lean phase pneumatic conveyors, for a range of particulate material. $7^{\text {th }}$ International conference on bulk materials storage, handling and transportation, Newcastle, Australia. 899-906.

Das, P.K. and Meloy, J.R. (2002). Effect of close-coupled bends in pneumatic conveying. Particulate science and technology, 20, 253-266.

Ito, H. 1959. Pressure losses in smooth pipe bends. Trans. ASME, Paper 59- Hyd-4.

Jones, M.G., and Williams, K.C. (2003). Solids friction factors for fluidized dense phase conveying. Particulate Science and Technology, 21,45-56

Marcus, R. D., Hilbert Jr, J.D. and Klinzing, G.E. 1984. The flow through bends in pneumatic conveying systems. Journal of Pipelines. (4), 103-112.

Klinzing, G.E., Marcus, R.D., Rizk, F., and Leung, L.S. (1997).Pneumatic Conveying of Solids -A Theoretical and Practical Approach. Publ. Chapman \& Hall.

Mills, D. and Mason, J.S. 1985. The influence of bend geometry on pressure drop in pneumatic conveying system pipelines. In the proceedings of 10International Conference Powder and Bulk Solids Handling, Chicago, IL, USA. Cahners Exhibition Group, Des Plaines, IL. 203-214.

Mills, D. (2004).Pneumatic conveying design guide ( ${ }^{\text {nd }}$ ed.).Oxford:Elsevier/ButterworthHeinemann.

Mallick, S.S. (2010). Modelling of fluidised dense-phase pneumatic conveying of powders.Doctoral Dissertation, University of Wollongong, Australia.

Pan, R. (1992). Improving scale-up procedures for the design of pneumatic conveyingsystems. Doctoral Dissertation, University of Wollongong, Australia. 
Pan, R., and Wypych, P.W. (1998) Dilute and dense phase pneumatic conveying of fly ash, 6th International Conference on Bulk Materials Storage and Transportation. Wollongong, NSW, Australia. 183-189.

Rossetti, S.J. (1983) Concepts and criteria for gas-solids flow, Handbook of fluids in motion, Ed. Nicholas P.Cheremisinoff and Remesh Gupta.Ann Arbor: Ann Arbor Science Publishers. 635-652.

Stegmaier, W. (1978). Zurberechnung der horinental enpneumatischen for de rungfeinkornigerfeststoffe - for the calculation of horizontal pneumatic conveying of fine grained solids.Fordern and Heben, 28. 363-366.

Schuchart, P. (1968). Widerstansgesetzebeimpneumatischen Transport in Rohrkrummern.Symposium series no. 27 (The Institution of Chemical Engineers). 65 72.

Singh, B., and Wolfe, R.R. (1972). Pressure losses due to bends in pneumatic forage handling.Transaction of the ASAE. 246-248.

Weber, M. (1981). Principles of hydraulic and pneumatic conveying in pipes.Bulk Solids Handling, 1, 57-63.

Williams, K.C. and Jones, M.G. (2004), Numerical model velocity profile of fluidised dense phase pneumatic conveying. $8^{\text {th }}$ International Conference on Bulk Materials Storage and Transportation, Wollongong, NSW, Australia. 354-358. 
Annexure A

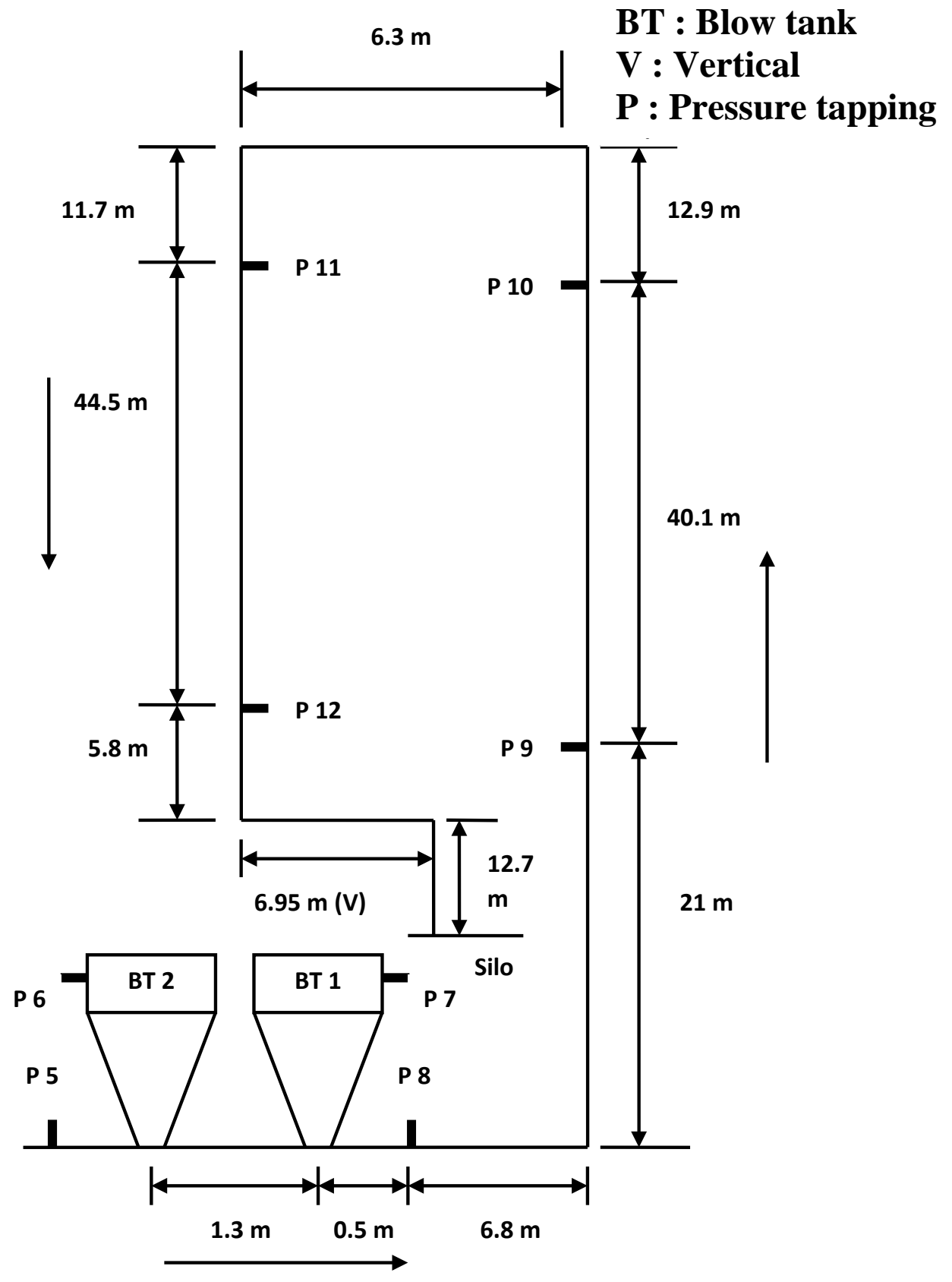

Fig. A1.Schematic of the 105 mm I.D. $\times 168$ m Long Test Rig (for fly ash) 


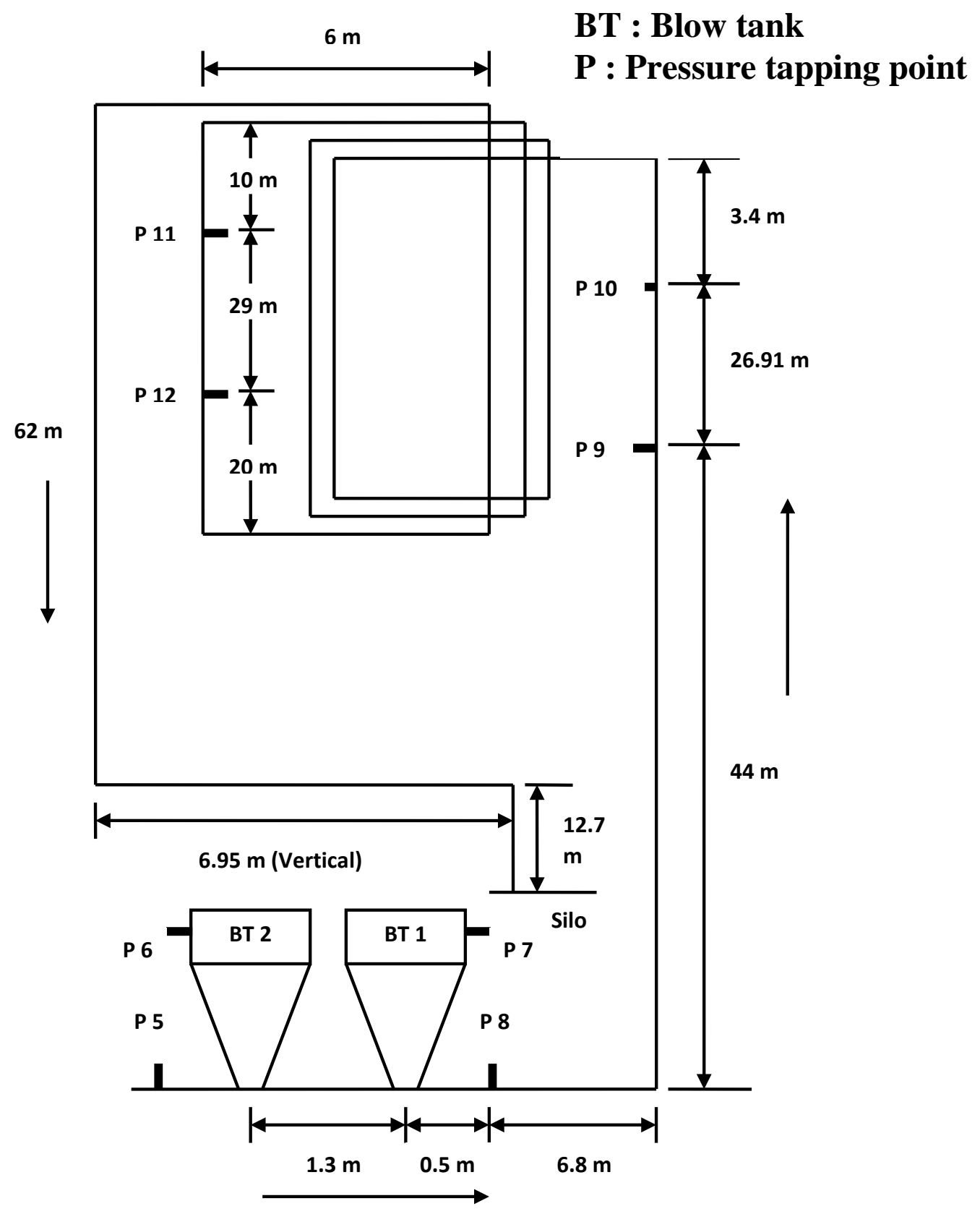

Fig. A2.Schematic of the 69 mm I.D. $\times 554$ m Long Test Rig (for fly ash) 